$15^{\text {th }}$ International Conference on

AEROSPACE SCIENCES \& AVIATION TECHNOLOGY,

ASAT - 15 - May 28 - 30, 2013, Email: asat@mtc.edu.eg,

Military Technical College, Kobry Elkobbah, Cairo, Egypt,

Tel: +(202) $24025292-24036138$, Fax: +(202) 22621908

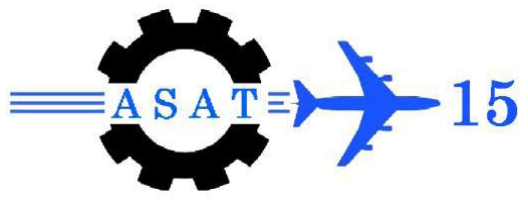

\title{
Effect of Projectile Shape on the Power of Fire in Personal Defense Hand-Held Weapons
}

\author{
M. S. Aboelkhair ${ }^{*}$, H. Yakout ${ }^{\dagger}$
}

\begin{abstract}
The category of arms which represent the group of Personal Defense Hand-held Weapons (PDHW) has special characteristics and requirements; among this wide range of characteristics is the request to gain high power of fire while retaining high mobility incorporated with high accuracy of fire. The old design $9 \mathrm{~mm}$ Parabellum which is still inservice has lost the credibility of securing the demands of the $20^{\text {th }}$ century soldier; this deficiency is represented in its low muzzle energy in spite of high recoil force which causes projectile instability during flight and loss of firing accuracy. In addition its bullet possesses bad ballistic shape which decreases the effective range.

In this paper, a comparative study was performed between two pistol calibers, the $9 \mathrm{~mm}$ old Parabellum and the same arm when modified and substituted by $5.56 \times 23 \mathrm{~mm}$ caliber. The exterior ballistics of both calibers was carried out using the PRODAS package. The aerodynamic coefficients and the trajectories were predicted and compared for both projectiles. The study reveals that using $5.56 \mathrm{~mm}$ caliber improves the power of fire, as well as the accuracy and stability. The study assures the importance of substitution of the in service $9 \mathrm{~mm}$ Parabellum with the $5.56 \times 23 \mathrm{~mm}$ which satisfies all combat and economical requirements as a personal defense hand hold weapon.
\end{abstract}

Keywords: Hand-held weapons, personal defense weapons, exterior ballistics, $5.56 \times 23 \mathrm{~mm}$, 9mm parabellum, drag, drift, dispersion, air resistance.

\section{Introduction}

The term "Hi Power of Fire" is a true classic definition to the range. When it was introduced early in the 20th century, the 9mm Parabellum Hi Power was a revelation. It offered the perfect balance of handling, size and firepower, with an impressive magazine capacity. Over the years, the Hi Power has aged gracefully and continues to have a loyal following among those "in the know". The Hi Power has proven itself around the world in the hands of lawenforcement, military, special operations forces and law abiding citizens. The power of fire ${ }^{N_{p}}$ includes all the parameters affecting economical, exploitation, mobility, and design requirements. This can be expressed in the following simple relation [1]:

$$
N_{p}=E_{M} K_{c o m b} P_{a c c}
$$

where $E_{M}$ is the projectile muzzle energy, $k_{c o m b}$ is the combat rapidity of fire, and $P_{a c c}$ is the probability of hitting the target (which is the measure of firing accuracy).

\footnotetext{
Egyptian Armed Forces, khair_mtc@yahoo.com ;

$\dagger$ Egyptian Armed Forces
} 
The Modified Parabellum-920 Hi Power is one of the most revered pistols of all time. Even though, its power is comparatively low if compared with the new generation of the PDHHW. Recently; a research leading to modify the Parabellum-920 with a $5.56 \mathrm{~mm}$ caliber was successfully completed, adding a valued piece of functional firearm to our collection of $\mathrm{Hi}$ Power pistol [2].

When a projectile is fired from a pistol, its momentum tries to keep it on a course in line with the pistol bore. Many forces act on the projectile during its flight in air before it reaches the target. Mainly, the earth's gravity, air resistance, wind and air currents force the projectile off its original course; and the spinning of the projectile tends to make it drift off course. All of these factors greatly alter the projectile's course and must be considered in determining how to elevate and traverse the pistol sight in order to hit the target [2,3]. Accuracy of fire is one of the main parameters affecting the power of fire; this parameter is also widely affected by the following variables:

1) Effect of gravity and air resistance,

2) Effect of projectile drift,

3) Effects of cross and range wind,

4) Effect of dispersion,

5) Effect of Vertical and horizontal parallax.

Exterior ballistics involves an analysis of the forces which act on the projectile and affect its course during flight from muzzle to target. It is also concerned with the practical problem of setting the weapon to incorporate ballistic corrections and enable a projectile fired from it to hit the target. The discussion will be limited to the factors involved in solving the problem of hitting a fixed target from a fixed position.

The main objective of our study is to hold a comparative study between the $9 \mathrm{~mm}$ pistol cartridge and the $5.56 \mathrm{~mm}$ cartridge for the same arm. As of Eq. 1, the power of fire depends on three parameters. Both the first and the second parameter are projectile wise dependant, while the third one is mainly related to the characteristics of the weapon itself. The study handles the parameters affecting projectile energy through finding the projectile velocities and ranges (at different angles of fire) for both cases, while the accuracy is well handled through the study of projectile drift.

\section{Exterior Ballistic Model}

During its flight, the projectile is acted upon by a number of forces. These include the gravitational force, aerodynamic force and Corioli's force accounting for earth rotation. The first one is normally assumed to be constant in magnitude and direction in case of exterior ballistic calculations, whilst the third one is customarily not considered, because of its negligible effect. The Modified-Point-Mass (MPM) projectile trajectory model was applied to predict the 3-D translatory motion of $9 \mathrm{~mm}$ and $5.56 \mathrm{~mm}$ pistol projectiles. The equation of projectile motion is given by [4, 5, 6 and 15]:

$$
q \frac{d \vec{v}}{d t}=\vec{F}_{D}+q \vec{g}+q \vec{\Lambda}
$$

where $q$ is the projectile mass, $\vec{v}$ is the projectile velocity vector, $\mathrm{t}$ is the travel time, $\vec{F}_{D}$ is the aerodynamic force which is composed of drag force $\vec{F}_{D 1}$ and Magnus force $\vec{F}_{D 2}, \vec{g}$ is the 
gravity acceleration vector, and $\vec{\Lambda}$ the Corioli's acceleration due to each rotation. The drag force encountered by the projectile due to its motion in air is expressed as:

$$
\vec{F}_{D 1}=-\frac{1}{2} \rho \mathrm{v}^{2} \mathrm{~S} \mathrm{C}_{\mathrm{D}}\left(M_{\#}\right) \widehat{\mathrm{v}}
$$

where v is the projectile velocity magnitude, $\rho$ is the local air density, $S$ is the projectile reference area $\left(=\pi d^{2} / 4\right), \mathrm{d}$ is the projectile caliber, $C_{D}\left(M_{\#}\right)$ is the projectile total aerodynamic drag coefficient, $M_{\#}$ is the local Mach number, and $\hat{v}$ is unit vector in the direction of projectile. The Magnus force due to projectile spinning motion is expressed as:

$$
\vec{F}_{D 2}=\frac{1}{2} \rho \mathrm{v}^{2} \mathrm{~S}\left(\frac{\mathrm{Pd}}{\mathrm{v}}\right) \mathrm{C}_{\mathrm{N}_{\mathrm{P} \alpha}}\left(M_{\#}\right)\left(\widehat{\mathrm{v}} \times \hat{\mathrm{i}}_{\mathrm{x}}\right) .
$$

where $\mathrm{P}$ is the projectile spinning rate $(\mathrm{rad} / \mathrm{s}), \hat{i}_{x}$ is unit vector in the direction of projectile axis of symmetry, and $C_{N_{P \alpha}}\left(M_{\#}\right)$ is the Magnus force aerodynamic coefficient. The Corioli's acceleration is given by the following expression:

$$
\vec{\Lambda}=2 \vec{\Omega} \times \vec{v} .
$$

where $\vec{\Omega}$ is earth angular velocity $\left(=7.292 \times 10^{-5} \mathrm{rad} / \mathrm{s}\right)$.

The projectile total aerodynamic drag coefficient is customarily decomposed into three components: (i) head drag coefficient $C_{D H}\left(M_{\#}\right)$, (ii) skin friction coefficient $C_{D S F}\left(M_{\#}\right)$, and (iii) total base drag coefficient $C_{D T B}\left(M_{\#}\right)$ that is determined by:

$$
C_{D}\left(M_{\#}\right)=C_{D H}\left(M_{\#}\right)+C_{D S F}\left(M_{\#}\right)+C_{D T B}\left(M_{\#}\right)
$$

The head drag experienced by the projectile is caused by compression waves generated ahead of the projectile path due to its motion in air. Its magnitude increases rapidly in the supersonic region due to the formation of the shock waves at the projectile nose. The skin friction is caused by shear stress developed due to the air viscous of the effect in the projectile wet area. Its effect on projectile motion is relatively small. The total base drag is mainly consists of base pressure drag, and boat-tail pressure drag (Eq. 7). The base pressure drag is caused by the formation of wake just behind the projectile tail. This region is attributed to the inability of air streamlines to follow the projectile profile. On other hand, the boat-tail pressure drag results from the pressure gradient developed along the boat tail surface [15].

$$
C_{D T B}\left(M_{\#}\right)=C_{D B P}\left(M_{\#}\right)+C_{D B T P}\left(M_{\#}\right)
$$

The exact theoretical determination of all aerodynamic coefficients for projectiles is not possible due to the dynamic motion and flow regimes encountered. The real trajectory, however, involves a spinning-yawing, axisymmetric body traversing large Reynolds and Mach number ranges.

An empirical [9, 10], and semi-empirical [14] codes have developed which are force-fitted to experimental trajectory observations and wind tunnel measurements. Wind tunnel and ballistic range tests are also possible ways of evaluation of aerodynamic coefficients. But they are generally too expensive and time-consuming [13]. When the projectile dynamic modes are exactly known and the Navier-Stokes equations valid, current computer modeling codes of the entire flow-field can give outstanding predictions for different speed regions. 
In this work, PRODAS software package was used to predict the aerodynamic characteristics of both projectile calibers together with trajectories at different angles of fire. The code utilizes an empirical modeling of the above-mentioned coefficients, while the trajectories were obtained by numerical integration of Eq.(2) using fourth-order Runge-Kutta scheme. The initial conditions are known as:

$$
t_{o}=0 ; x_{o}=0 ; y_{o}=0 ; z_{o}=0 ; u_{o}=v_{o} \cos \theta_{o} ; w_{o}=v_{o} \sin \theta_{o} ; \dot{z}_{o}=0 .
$$

where $v_{o}$ and $\theta_{o}$ are the projectile muzzle velocity and angle of fire, respectively.

The partial atmospheric data as function of height y (i.e. specific mass $\rho_{\infty}$, atmospheric pressure $p_{\infty}$, and air temperature $T_{\infty}$ ) for height $<11000 \mathrm{~m}$ are given in the following formulas:

$$
\begin{aligned}
& \rho_{\infty}=\rho_{\text {on }}\left[1-e_{1} y / T_{\text {on }}\right] e_{2}, \\
& p_{\infty}=p_{\text {on }}\left[1-e_{1} y / T_{\text {on }}\right] e_{3}, \\
& T_{\infty}=T_{\text {on }}-e_{1} \cdot y
\end{aligned}
$$

where $\rho_{o n}, p_{o n}$, and $T_{\text {on }}$ are the atmospheric conditions at the sea level, $\mathrm{e}_{1}, \mathrm{e}_{2}$, and $\mathrm{e}_{3}$ are constants equal to $6.5 \times 10^{-3}, 4.256$ and 5.256 , respectively.

\section{Very Low Drag Bullets}

The idea of introducing Very Low Drag (VLD) bullets is primarily approved within small arms ballistic development in the early of the 1980s, in order to reach higher degree of accuracy and kinetic energy, which in turn improves the power of fire. This demand is urgent for all automatic weapons; especially the military snipers, long range target shooters, including F-class and bench rest competitors. The recent work adopts VLD idea to be applied in the pistol category of HHW. Bullets with a lower drag coefficient decelerate less rapidly. A low drag coefficient flattens the projectile's trajectory somewhat at long ranges and also markedly decreases the lateral drift caused by crosswinds.

VLD bullets feature the objective of supreme long range design. With both an extra long nose and a boat tail, these bullets have the highest possible ballistic coefficient. They shoot flatter and are less affected by wind conditions than any other bullet of similar weight. You don't need super-high velocity for flat trajectories with VLD bullets. The design allows the bullet to shoot flatter at any velocity. For best results, the bullet should be touching the rifling when loaded. It is recommended for $300 \mathrm{~m}$ or more and will not work in most magazines [7].

To reduce the eccentricity of bullet geometrical axis and to be coincident with the centers of mass, and to use carefully tapered bullet heels, or boat-tails [15] as shown in Fig.1 where the bullet shown in Fig.1.a represent the Flat Base Spitzer Soft Point (FSSP) projectile, Fig.1.b is the Boat Tail Spitzer Soft Point (BTSP), Fig.1.c is the Round Nose Soft Point (RNSP), Fig.1.d is the Round Nose Full Metal Jacket (RNFMJ), Fig.1.e is the Flat Nose Soft Point (FNSP), and Fig.1.f is the Boat Tail Full Metal Jacket (BTFMJ) projectile. 


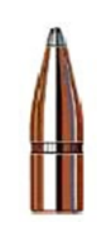

a

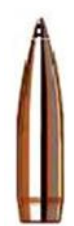

b

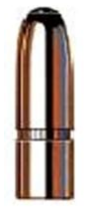

c

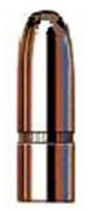

d

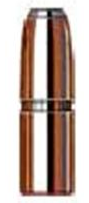

e

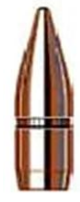

f

Fig.1 Different geometrical projectile shapes which secure very low drag

In order to reduce the air resistance, improve the aerodynamics of projectile, the bullet nose design and construction could incorporate either a secant or tangent ogive. On the other hand; the possibility to machine mono-metal bullets offers designers the freedom to design slender aerodynamically efficient bullet shapes that cannot be produced with more traditional bullet production methods. Mono-metal very-low-drag bullets are normally machined from solid bars of highly-machinable metals using CNC lathes. Common materials include UNS C36000 Free-Cutting Brass, Oxygen-free copper and other highly machinable alloys of copper, nickel, and tellurium.

\section{Basic Dimensions of the Projectile used Models}

Producing accurate bullets this way is not easy. To guarantee consistency and hence accuracy professional quality control during and after production is needed. Mono-metal solid bullets are more expensive than traditional jacketed Hollow Point Boat-Tail very-low-drag bullets. In future research a traditional Hollow Point Boat Tail VLD pistol bullets are put under research to be produced. The jackets of these bullets are generally made out of copper alloy (such as gilding metal or cupronickel. The resulting projectile should be very "slippery" (well streamlined) for easier passage through the air. The relative dimensions of the projectile models used in the mathematical model are presented in terms of their caliber as shown in Figs.2, 3. And their approximate numerical values are listed in Table.1

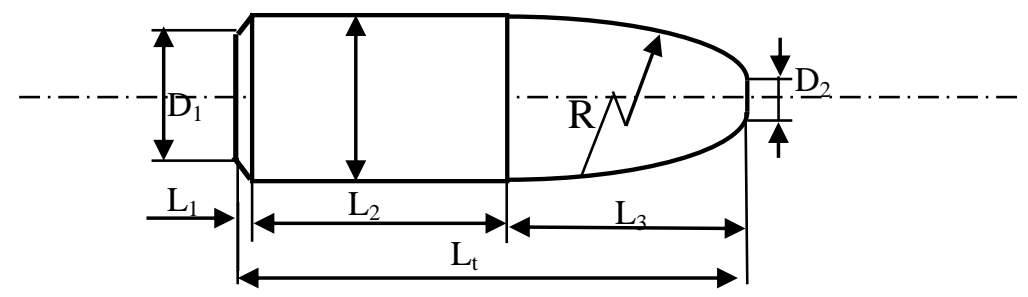

Fig.2 The relative dimensions for $9 \mathrm{~mm}$ in terms of projectile caliber

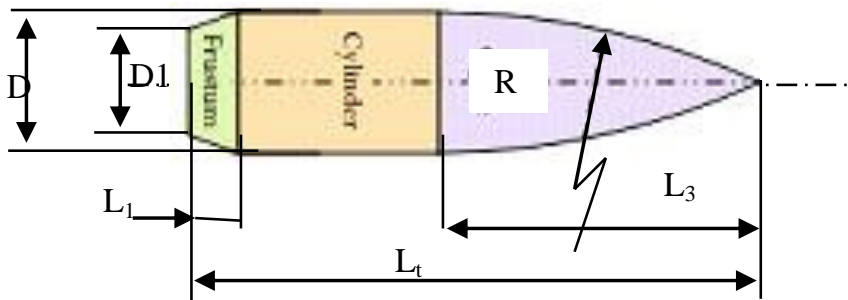

Fig.3 The relative dimensions for $5.56 \mathrm{~mm}$ in terms of projectile caliber. 
Table 1. Relative main dimensions of $9 \mathrm{~mm}$ and $5.56 \mathrm{~mm}$ projectiles

\begin{tabular}{|c|c|c|}
\hline$\overline{\text { Dimensions [mm] }}$ & $9 \times 18 \mathrm{~mm}$ Parabellum & New $5.56 \times 23 \mathrm{~mm}$ \\
\hline Caliber, & $9 \mathrm{~mm}$ & $5.56 \mathrm{~mm}$ \\
\hline Base diameter, $\quad \mathrm{D}_{1}$ & 0.95 & 0.75 \\
\hline Nose diameter, $\mathrm{D}_{2}$ & 0.30 & 0.05 \\
\hline Ogive diameter, $\mathrm{R}$ & $2.5: 3$ & 6 \\
\hline Total length, & 2.5 & $4: 4.2$ \\
\hline Boattail length $\mathrm{L}$ & 0.05 & 0.2 \\
\hline Cylindrical length & 1.7 & 1.5 \\
\hline Ogive length & 0.75 & 2.5 \\
\hline Boattail angle $\alpha_{0}$ & $<1^{\circ}$ & $2: 3^{\circ}$ \\
\hline
\end{tabular}

\section{Results and Discussions}

In order to present the effect of shape characteristics on the ballistic characteristics and projectile performance for small caliber ammunition; a real data for the $9 \mathrm{~mm}$ Parabellum and the $5.56 \times 23 \mathrm{~mm}$ new NATO pistol caliber are applied. The real data are used to feed the ballistic software package PRODAS [5], the results show interesting comparative values between the two types. As well known; both calibers are used in a class of PDHHW type weapon, since they are belonging to the same class from the point of view of purpose and property; the study concentrates on the parameters affecting the range, the drag, the resisting forces, and the drift. All the mentioned parameters have been studied thoroughly in a comparative study; and the results are listed as follows:

\subsection{Drag Affecting the Flight in Both Types}

As well known; drag is an important parameter affecting the range and accuracy of fire. The effect of the geometrical variation in shape of both types are considered, and the drag affecting each type at the same conditions of I.V and same angle of fire calculated, then graphed and listed as shown in Fig.4.

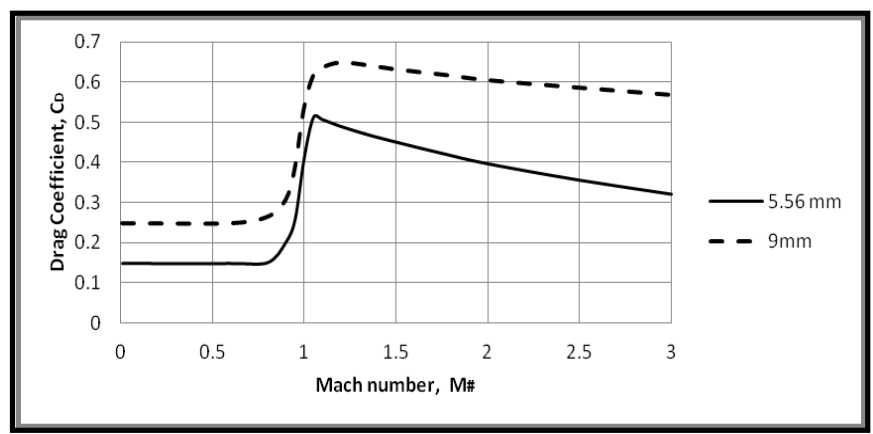

Fig.4 Total base drag coefficient for $9 \mathrm{~mm}$ and $5.56 \mathrm{~mm}$ projectiles

The results of the total drag coefficient obtained from calculations show that the base drag is the dominant component if compared with other drag components presented byEqs.7 and 8 . For the $9 \mathrm{~mm}$ projectile; the this coefficient reaches 0.25 at subsonic velocities, 0.66 at transonic velocities and about 0.6 in the supersonic region, and the total base drag coefficient for the case of $5.56 \mathrm{~mm}$ projectile reaches 0.14 at subsonic velocities, 0.52 at transonic velocities and about 0.41 in the supersonic region. That is probably prove the importance of 
research activities concerning range extension has been mostly concerned with reducing base drag, particularly via the change in boattail and ogive geometry, as well as the other relative dimensions of projectiles.

\subsection{Spin Deceleration Coefficient and Projectile Drifting}

The rifling of the pistol barrel causes the projectile to rotate during flight with sufficient rapidity to behave as a gyroscope. This serves to stabilize the flight of the projectile, but it makes the projectile subject to gyroscopic precession. Because of the curvature of the trajectory, air pressure on the underside of the nose of the projectile causes a precession to the right. This shift of the projectile axis to the right increases the air pressure on the left-hand side of the nose, which causes the projectile to presses downward. Both the variation of spin deceleration coefficient and the drift of projectile along the trajectories are calculated and included as shown in Figs. 5, 6 respectively.

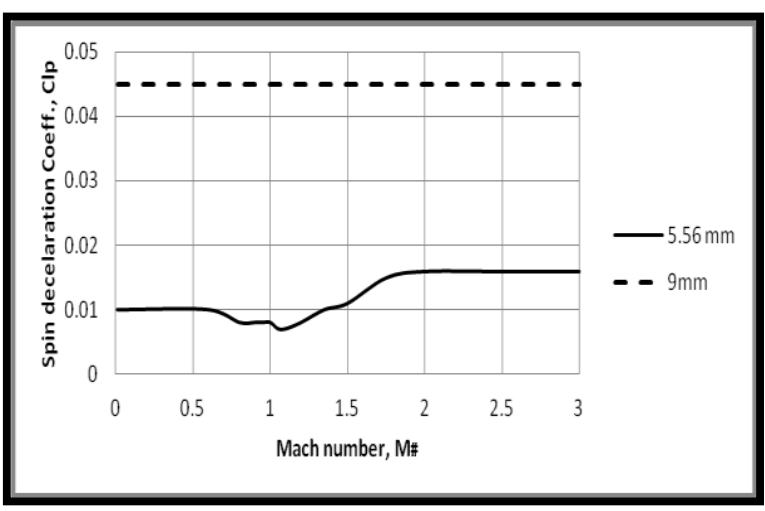

Fig.5 Absolute spin deceleration coefficient vs. M\#

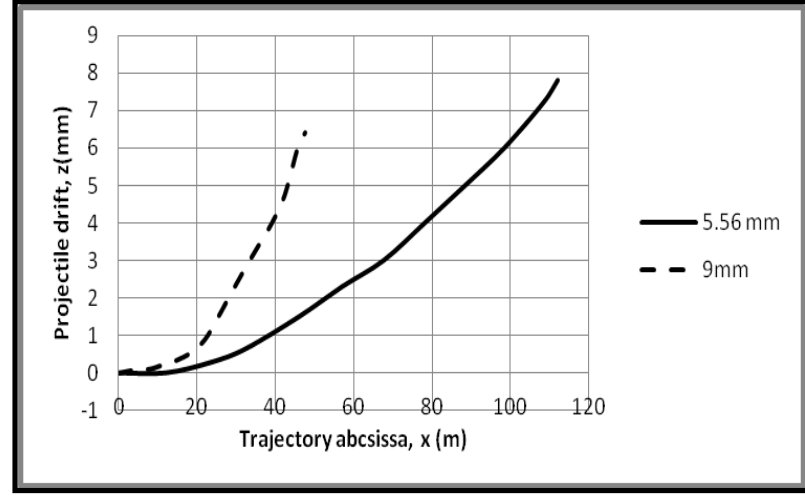

Fig.6 Projectile drift variation along the trajectory

\subsection{Magnus Force Variation}

The lift generated by an airfoil depends on such factors as the speed of the airflow, the density of the air, the total area of the airfoil, and the angle of attack. The angle of attack is the angle at which the airfoil meets the oncoming airflow. A symmetric airfoil must have a positive angle of attack to generate positive lift. At a zero angle of attack, no lift is generated. At a negative angle of attack, negative lift is generated. A cambered airfoil may produce positive lift at zero, or even small negative angles of attack. The Magnus force coefficient is calculated for both types of cartridges; and throughout variation of Mach number from 0-3, then graphed and listed as shown in Fig.7.

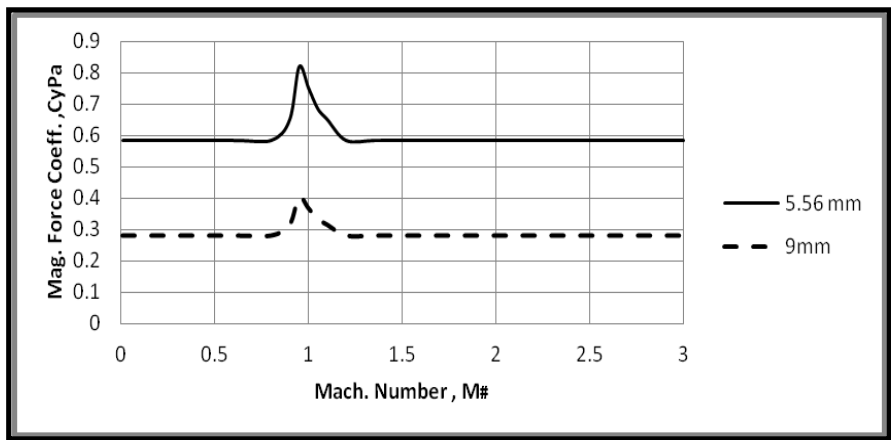

Fig.7 Absolute Magnus force coefficient variation vs. Mach number 


\subsection{Effect of Angle of Elevation on the Range}

Since the study is concerned with a small caliber projectile, this type of weapons are characterized by direct fire within a relatively short distances, then the angles fed to the program is $0.25^{\circ}>\theta<5^{\circ}$, and the results are graphed and listed in Fig.8 and Fig.9.

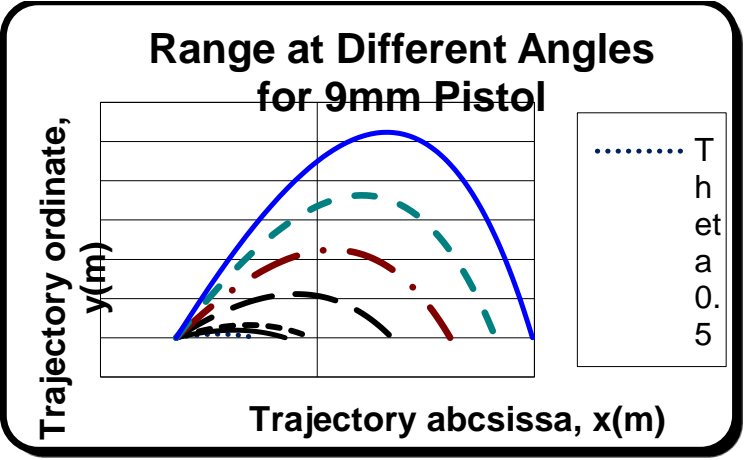

Fig.8 Range variation with the change of firing angle of $9 \mathrm{~mm}$ cartridge

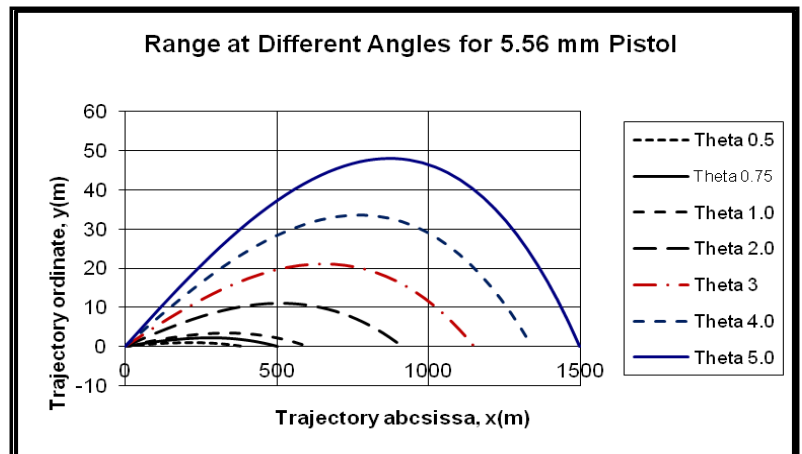

Fig.9 Range variation with the change of firing angle of $5.56 \mathrm{~mm}$ cartridge

\subsection{Effect of the Angle of Fire Variation on the Angle of Impact}

For the maximum firing range corresponding to varying angles of fire between $0,25^{\circ}>\theta<5^{\circ}$, the angle of impact of the projectile at the maximum range for both calibers are calculated, then graphed and listed as shown in Fig.10.

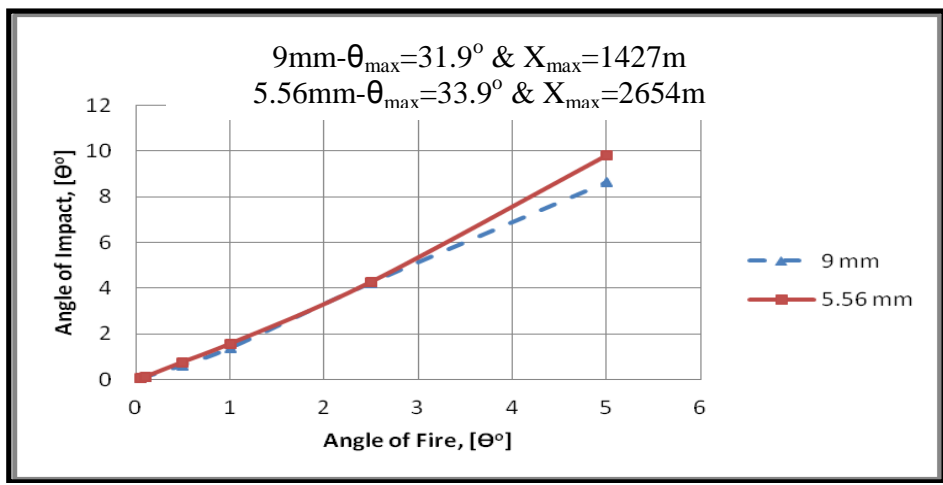

Fig.10 Relation between angle of fire and impact angle for both calibers

\subsection{Effect of Angle of Fire on the Time of Flight}

The effect of the change in the firing angle and I.V. on the time of flight for both calibers is calculated, and then graphed as shown in Fig.11 following:

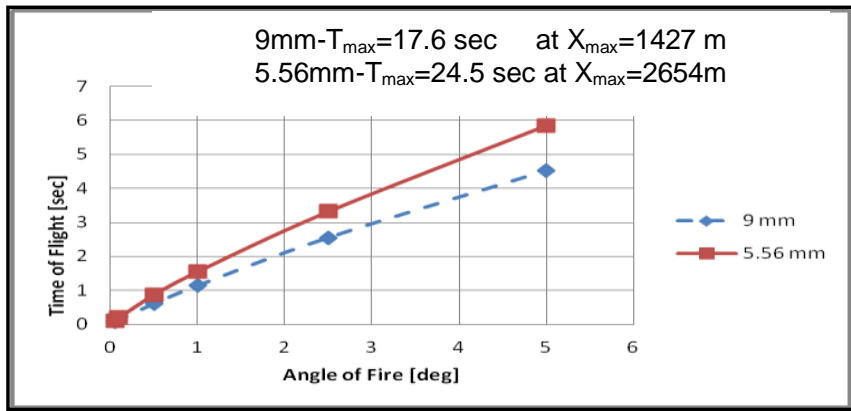

Fig.11 Effect of angle of fire variation on the time of flight 


\subsection{Impact Velocity Variation at Specific Angle:}

One of the most important parameters is the hit velocity of projectile at the target, The effect of the change in the firing angle on the velocity of impact at firing angle $\theta=5 \mathrm{o}$ are calculated, then graphed and listed as shown in Fig.12.

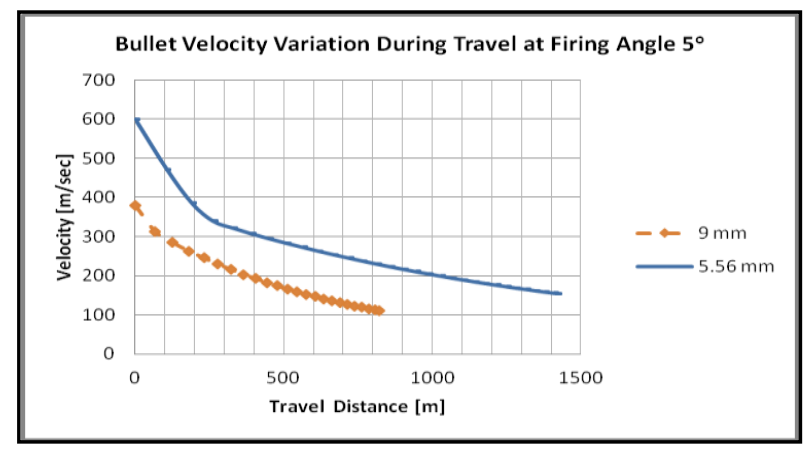

Fig.12 Impact velocity variation along the range at firing angle $\theta=5^{\circ}$

\subsection{Effect of Angle of Fire on the Range and Height of Both Calibers:}

One of the most effective combat properties of both PDHHW is the range or altitude of the projectile corresponding to a certain angle of fire, These values are calculated for firing angles between $0,25^{\circ}>\theta<5^{\circ}$, and the resulting range and height are obtained, then graphed as shown in Figs.13, 14.

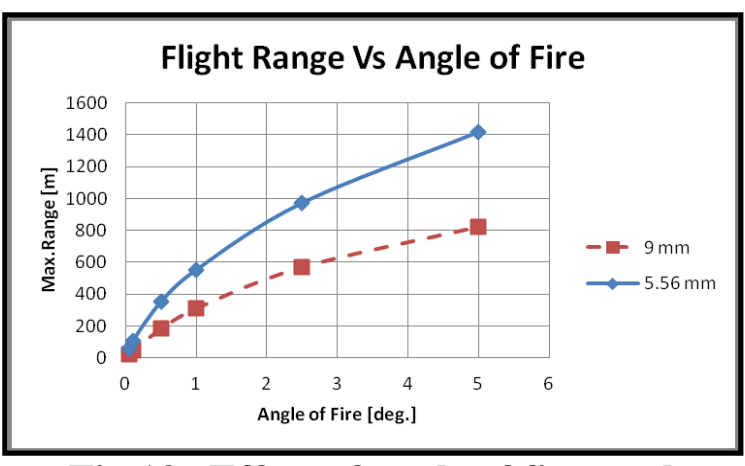

Fig.13 Effect of angle of fire on the maximum range of projectiles

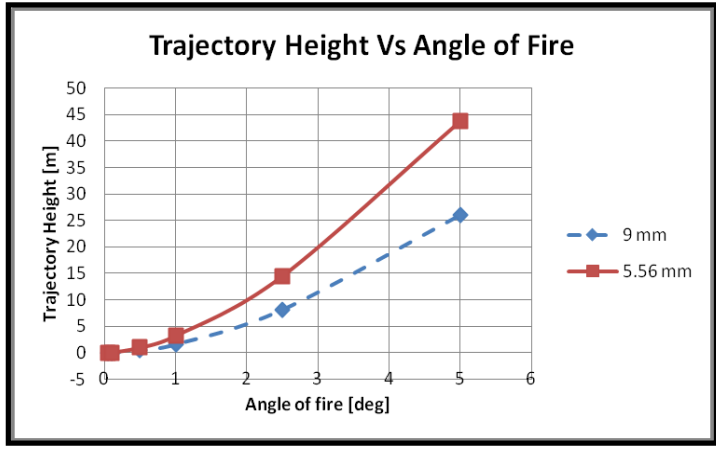

Fig.14 Effect of angle of fire on the trajectory heights

\subsection{Projectile Angle Variation During Flight}

The continues change of the projectile angle during flight characterize the adhesion of the projectile to the trajectory, abrupt and sudden changes; as well as the value of change indicates the stability, the calculation results prove that the rate of change of this parameter with the $9 \mathrm{~mm}$ projectile is greater than that of the $5.56 \mathrm{~mm}$, this result explains why the real firing tests proves that the $9 \mathrm{~mm}$ accuracy at $50 \mathrm{~m}$ firing is $10 \%$ of that with the second type [3], and the absolute variation of this angle is presented in Fig.15 


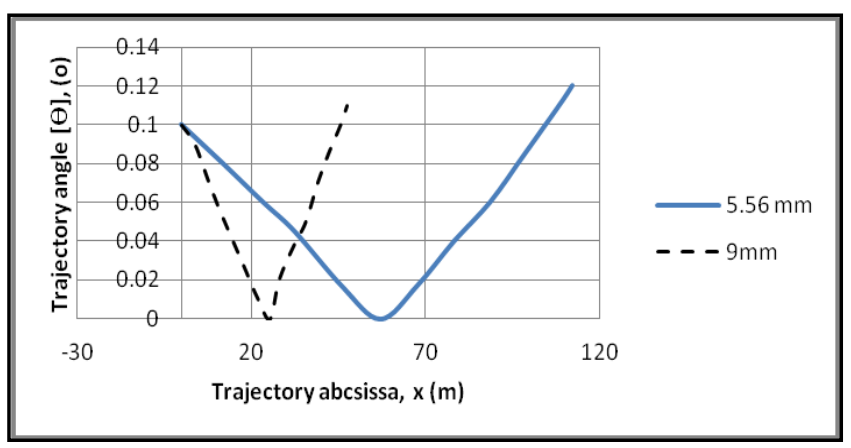

Fig. 15 Absolute variation of trajectory angle along the trajectory

\subsection{Velocity and Energy Variation}

Referring to the energy of projectile, this parameter is the key point of evaluating the power of fire, this parameter is calculated for both projectiles; it is important to include that in spite of having the weight of the $9 \mathrm{~mm}$ projectile is more greater than twice the weight of the $5.56 \mathrm{~mm}$, the energy of the second type is always greater than that of the $9 \mathrm{~mm}$. This is presented clearly by Figs.16, 17.

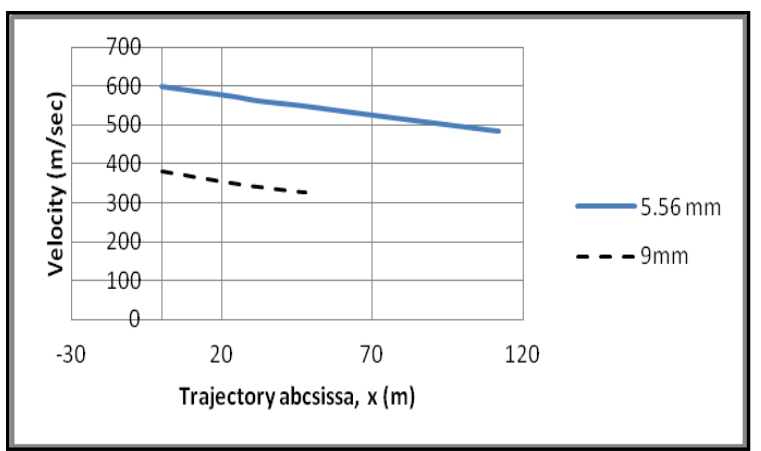

Fig.16 Projectile velocity drop along the trajectory

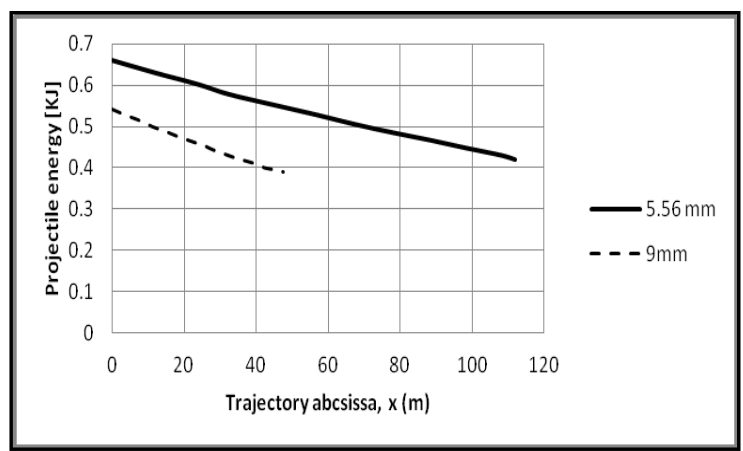

Fig.17 Projectile energy drop along the trajectory

\section{Conclusions}

The analysis of the above studied and calculated ballistic parameters for both calibers, $9 \mathrm{~mm}$ and $5.56 \mathrm{~mm}$ of a PDHHW explains and verifies the following main points:

- In spite of reducing the caliber, the propellant charge, and weight of projectile for the $5.56 \mathrm{~mm}$ when compared with the geometrical data of the $9 \mathrm{~mm}$, the power of fire of the first exceeds that of the $9 \mathrm{~mm}$.

- Dispersion and the accuracy of fire of the $5.56 \mathrm{~mm}$ bullet are much better than that of the $9 \mathrm{~mm}$ especially within its effective range $(200: 300 \mathrm{~m})$. Firing results prove that the improvement reduces the average area of fall from $12 \times 15 \mathrm{~cm}$ to $4 \times 5 \mathrm{~cm}$ at $50 \mathrm{~m}$ [2].

- The maximum range of the $5.56 \mathrm{~mm}$ exceeds almost double the range of the $9 \mathrm{~mm}$ while keeping a projectile velocity sufficient to produce the energy which causes the hydrodynamic effect on life targets, as referenced 50:80 Joule [14].

- Noticeable reduction of air resistance opposing to projectile motion for the case of the $5.56 \mathrm{~mm}$ bullets due to the improve in its ballistic shape, also the drag and the drift have reached a reasonable improvements which appears noticeably on the range, height, drag and drift results. 
In general, it is advised to make a surgical decorative operation through a limited change to only 4 components from the counted 52 components of the $9 \mathrm{~mm}$ Parabellum to create the PDHHW of caliber $5.56 \mathrm{~mm}$, this operation economically saves much money while the combat properties of the new caliber is extremely improved and enhanced. On other hand it is possible with the new caliber to manufacture Armour Piercing type of ammunitions to face protected targets. The most important issue which can be derived from this study is that beside the improvement in the performance of ammunition, the recoil energy of the $5.56 \times 23 \mathrm{~mm}$ pistol moving components has reached almost $50 \%$ from that calculated with the case of $9 \mathrm{~mm}$ using same muzzle velocity. Such reduction improves the stability of the pistol during fire and enhances its firing accuracy.

\section{References}

[1] Anonyms, Theory and Design of Small Arms, P.L. No.40, MTC, Cairo, Egypt, 1960.

[2] Aboelkhair, M.S., MOD, Egypt, R\&D Research 1998, Final Proto-type, July 2005.

[3] Anonyms, Ballistics Measurement and Testing of Ammunition, P.L. No.1178, MTC, Cairo, Egypt, 1962.

[4] Anonyms, Principle Problems of Theoretical Internal Ballistics, P.L. No. 717, MTC, Cairo, Egypt, 1960.

[5] Anonyms, PRODAS Technical Manual, Arrow Tech. Associates, VA. 1993.

[6] Carlucci; D.E. and Jacobson, S.S., Ballistics: Theory and Design of Guns and Ammunition, Taylor \& Francis Group, CRC Press, FL, 2008, pp. 246-255.

[7] Donald E. C., Sidney S. J. "Ballistics: Theory and Design of Guns and Ammunition", Taylor and Francis Group, CRC Press, US, 2008

[8] McCoy, R.L., Modern Exterior Ballistics, Schaffer Publishing Ltd., PA, pp. 212-220, 1999.

[9] El-Ashmawy, A.R., "Drag Prediction Methodology for Missiles at Subsonic, Transonic \& Supersonic Speeds", M.Sc. Thesis, MTC, Cairo, Egypt, 1986.

[10] Hamilton, S., "Forensic Ballistics: Styles of Projectiles". Reinforced Library Edition, USA, 2008.

[11] Lebeqev, A.A. and Chernobrovsky, L.S., "Flight Dynamics", Mir Publishers, Moscow, 1993.

[12] Robert A. R., "Understanding Ballistics", Joseph D'Alessandro editors, , Mulberry House Publishing, California, USA, 1997.

[13] Robert L. McCoy, Modern Exterior Ballistics: The Launch and Flight Dynamics of Symmetric Projectiles, Amazon Press, Schaffer Publishing, 1999 and January 2004.

[14] Shiau, N. H., "Numerical Simulation of the Aerodynamics of Turbulent Transonic Flow Past a Projectile", Ph.D. Thesis, University of Florida, 1987.

[15] Yakout, H. and Abdel-Kader, M.S., "Range Extension via Base Bleeding", 4th AME Conf., MTC, Cairo, Egypt, 1990, pp.29-42. 